\title{
Late Recurrence in a Rectal Cancer Patient Who Underwent Preoperative Chemoradiotherapy Followed by Local Excision: A Case Report
}

\author{
Jin Soo Han ${ }^{1}$, Seok-Byung Lim ${ }^{1}$, Jin-hong Park ${ }^{2}$, Yong Sang Hong ${ }^{3}$ \\ ${ }^{1}$ Division of Colon and Rectal Surgery, Department of Surgery, ${ }^{2}$ Department of Radiation Oncology, ${ }^{3}$ Department of Oncology, Asan Medical \\ Center, University of Ulsan College of Medicine, Seoul, Korea
}

Some patients who have undergone preoperative chemoradiotherapy (CRT) following surgery have been diagnosed with late recurrence more than 5 years after treatment, raising questions about the possible benefit extending surveillance beyond the recommended 5 years. In 2011, a 71-year-old male patient was diagnosed with T3N+ low-lying rectal cancer located $3 \mathrm{~cm}$ from the anal verge before undergoing long-course preoperative CRT. After CRT, the patient was reexamined and diagnosed with ycT1-2N0 lesion, so local excision (LE) was performed. The patient underwent intensive surveillance for up to 5 years, and no evidence of recurrence was found. At 74 months after surgery, the patient was hospitalized for a hematochezia, and local recurrence at the excision site and peritoneal seeding nodules were identified. Considering the late recurrence in this patient, it might be necessary to long-term follow-up beyond 5 years in patients with preoperative CRT followed by LE.

Keywords: Rectal neoplasms; Chemoradiotherapy; Recurrence

\section{INTRODUCTION}

In locally advanced mid or low rectal cancer, total mesorectal excision (TME) after preoperative chemoradiotherapy (CRT) is established as the standard treatment. However, some patients experience morbidity such as urinary or sexual dysfunction after TME, and some patients live with a permanent stoma. Recently, interest in alternative organ-preserving methods such as local excision or 'watch and wait' has increased as tolerable oncologic outcomes have been reported [1].

Although comprehensive surveillance is important to identify

Received: Feb 10, 2020 - Revised: Mar 13, 2020 - Accepted: Mar 16, 2020 Correspondence to: Seok-Byung Lim, M.D.

Division of Colon and Rectal Surgery, Department of Surgery, Asan Medical Center, University of Ulsan College of Medicine, 88 Olympic-ro 43-gil,

Songpa-gu, Seoul 05505, Korea

Tel: +82-2-3010-5695, Fax: +82-2-3010-6701

E-mail: sblim@amc.seoul.kr

ORCID: https://orcid.org/0000-0001-8824-4808

(C) 2021 The Korean Society of Coloproctology

This is an open-access article distributed under the terms of the Creative Commons Attribution NonCommercial License (https://creativecommons.org/licenses/by-nc/4.0) which permits unrestricted non-

commercial use, distribution, and reproduction in any medium, provided the original work is properly cited. recurrence, no precise timeframes or methods have been established. Most recurrences occur within 5 years after surgery [2], so standard surveillance is performed for up to 5 years [3], but the appropriate follow-up period for CRT followed by local excision has still not been established. Recently, some patients who underwent preoperative CRT following local excision were diagnosed with recurrence more than 5 years after treatment, raising questions about the possible benefit of prolonging surveillance beyond the recommended 5 years [4].

Here, we report the case of a 71-year-old male with late local recurrence and peritoneal seeding almost 74 months after preoperative CRT and local excision.

\section{CASE REPORT}

A 71-year-old male patient visited a local clinic in July 2011 with symptoms of bowel habit change and hematochezia. An ulcerofungative huge mass ( $4 \mathrm{~cm}$ on endoscopy) was observed in the low rectum and pathologically confirmed to be moderately differentiated adenocarcinoma.

The patient visited our center and performed rectal magnetic resonance imaging (MRI), transrectal ultrasonography, abdomi- 
nopelvic computed tomography (CT), chest CT, and whole-body positron emission tomography-CT. The cancer was identified 3 $\mathrm{cm}$ from the anal verge with perirectal fat infiltration, multiple lymph nodes, and suspected metastasis, but distant metastasis was not observed (cT3N1-2M0) (Fig. 1A).

Long-course preoperative CRT was initiated in August 2011 for 6 weeks with 5-fluorouracil plus leucovorin and a radiation dose of 5,040 cGy in 25 fractions was administered in the pelvic area. Six weeks after completion of CRT, the patient was reexamined with rectal MRI, transrectal ultrasonography, abdominopelvic CT, and flexible sigmoidoscopy imaging and showed good response to CRT (ycT1-2N0) (Fig. 1B). The patient was evaluated by a multidisciplinary team and underwent local excision.

On November 16, 2011, transanal excision was performed and residual adenocarcinoma of $0.4 \mathrm{~cm}$ size with moderate regression grade was confirmed with pathology. Lymphovascular invasion or perineural invasion was not seen and the resected margin was clear, but perirectal soft tissue extension was seen (ypT3). Although salvage TME was recommended, the patient refused additional surgery or adjuvant chemotherapy.

The patient underwent intensive surveillance with 3 months intervals using carcinoembryonic antigen (CEA) and sigmoidoscopy in the first year following surgery and at 6 months intervals using CEA, colonoscopy with biopsy, abdominopelvic CT, and
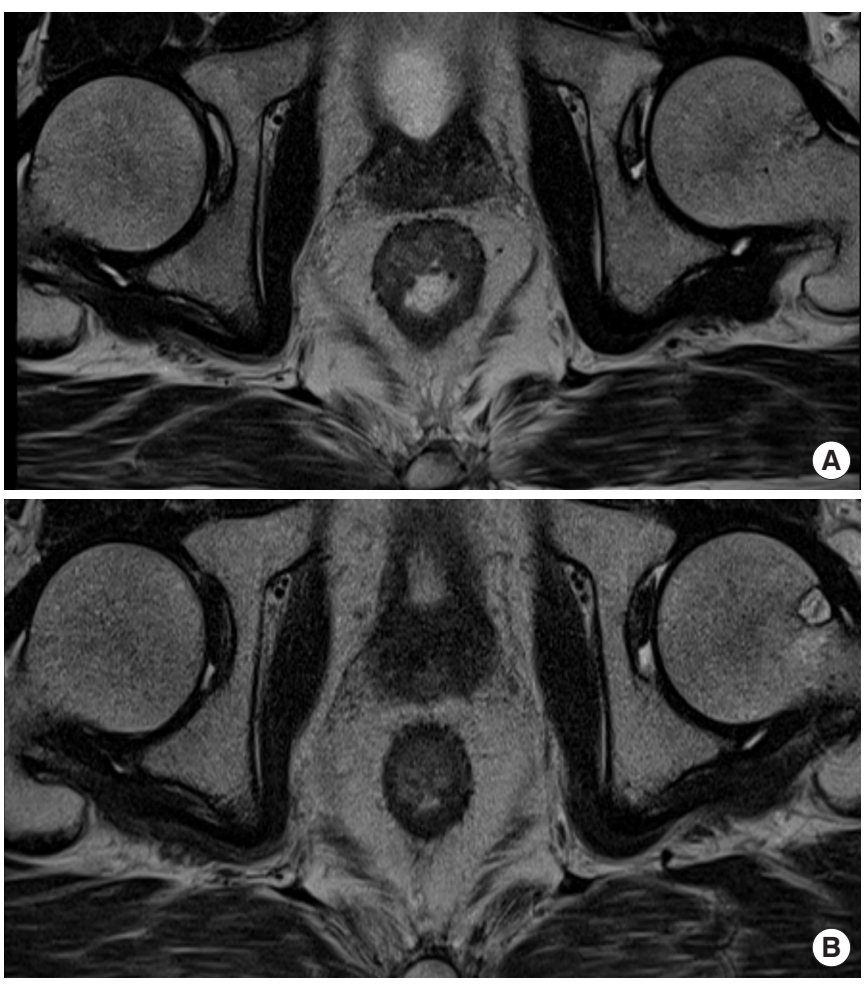

Fig. 1. Rectal magnetic resonance imaging of the patient. (A) Before preoperative chemoradiotherapy (CRT) (cT3). (B) Restaging after preoperative CRT (ycT1-2). chest CT imaging from the 2nd to 5th years. During the 5-year surveillance period, the patients underwent a total of 11 times endoscopic examinations and 6 times biopsy. The pathology findings of each biopsy showed 1 ulcer detritus, 3 granulations, 1 ulcer detritus, and 2 chronic proctitis. During this period no evidence of recurrence was found. After 5 years, annual follow-up was planned but surveillance was not performed due to the patient being lost to follow-up.

At 74 months after surgery, the patient was rehospitalized for hematochezia and anal pain. In sigmoidoscopy images, ulceration was observed at the previous surgical site and local recurrence was suspected. Abdominopelvic CT images showed diffuse wall thickening of the rectum, multiple enlarged lymph nodes in the perirectum, and irregular thickening of the peritoneum (Fig. 2). As a peritoneal seeding nodule was suspected, open excisional biopsy of the peritoneal nodule was performed, revealed a malignant cell. The patient underwent 15 cycles of systemic chemotherapy with FOLFOX (folinic acid, fluorouracil, and oxaliplatin) plus bevacizumab. No further chemotherapy has been performed due to poor oral intake and nephropathy, and the patient is currently receiving hospice care.

Written informed consent was obtained for this report and accompanying images.

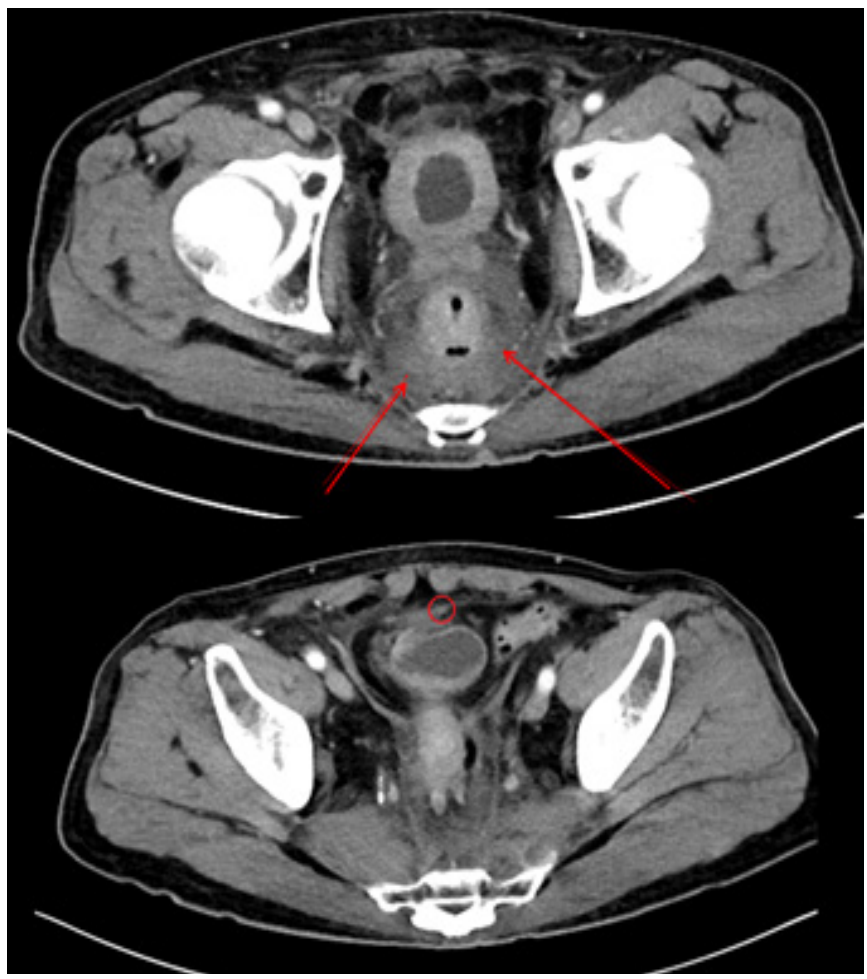

Fig. 2. Computed tomography images revealed local recurrence at the local excision site, peritoneal thickening (arrows), and suspected seeding nodules (circle). 


\section{DISCUSSION}

In low rectal cancer, local excision is not recognized as a standard treatment except for selected patients with early-stage cancer (T1) patients or patients who cannot undergo TME [5]. However, preoperative CRT has become more common in locally advanced rectal cancer and the role of local excision has increased, with tolerable oncologic outcomes such as clinical complete response or near-complete response reported even in cT3N+patients. As more attention is paid to organ preservation and surgery deferral strategies, local excision is used to identify pathologic complete response $[6,7]$.

More intensive surveillance is required to detect recurrence after local excision than is necessary for general surveillance after standard colorectal cancer surgery, but no guidelines for this intensive surveillance are available. Several studies have reported late recurrence of colorectal cancer, with $0.9 \%$ to $4.6 \%$ of patients developing recurrence after 5 years [2, 8-10]. There have been some reports of late recurrence after local excision, but the exact incidence is not clear. Paty et al. [11] reported that only 1 of 23 patients developed local recurrence after local excision after 5 years.

No consensus has been reached regarding which risk factors are associated with late recurrence of colorectal cancer. Some studies reported that patients who experienced late recurrence were more likely to be male and have low preoperative CEA, smaller tumor size, well-differentiated tumors, and no lymph node metastasis [2, 10]. Merkel et al. [9] reported that late recurrence occurred more frequently in patients with low $\mathrm{pN}$ stage and low-grade tumor. Some studies also reported that local recurrence may be delayed in patients who undergo radiotherapy [11-13]. Chakravarti et al. [4] also reported that 4 of 47 patients developed local recurrence at $64,72,86$, and 91 months in the adjuvant irradiation group and underscored the need for careful long-term follow-up in these patients. The patient in this case had several of these characteristics, such as being male; having low preoperative CEA, no tumor cell dissemination; and having undergone radiotherapy. In terms of tumor size, Cho et al. [2] suggested the possible relation between small-sized tumors and the late recurrence. However, the small tumor size $(0.4 \mathrm{~cm})$ of the patient in this case was shown after preoperative CRT and there is little evidence that tumor size was a significant factor in late local recurrence after preoperative CRT. They included cases of previous studies [2, 9-13] reporting the risk factors associated with late recurrence were heterogeneous. They were not limited rectal cancer, and local excision study [11] included only early $\mathrm{T} 1-2$ rectal cancer patients. Therefore, there is little evidence of the risk factor for late recurrence in rectal cancer patients treated preoperative CRT following local excision.

Even after local recurrence has occurred, early detection through appropriate surveillance can prevent disease progression through salvage surgery and improve overall survival [14]. Patients who undergo local excision generally require more active surveillance, and patients with a higher probability of late recurrence will re- quire continued surveillance beyond 5 years. In this case, when evaluation continued the pathologic stage had progressed to ypT3, so additional salvage operation was possible but not done. After that, the patient was lost to follow-up for approximately 1 year, and the peritoneal seeding had already progressed. In ypT2 or higher $\mathrm{T}$ stages, local excision alone is insufficient due to the likelihood of local recurrence [15]. However, despite warnings about these risks, some patients may refuse to proceed with the further salvage operation. It is important to develop a treatment plan for patients with careful consideration of these issues.

In conclusion, we experienced a case of late local recurrence and peritoneal seeding almost 74 months after local excision followed by preoperative CRT. Considering the late recurrence, it is necessary to consider periodic follow-up even after 5 years, especially for patients at high risk of late recurrence.

\section{CONFLICT OF INTEREST}

No potential conflict of interest relevant to this article was reported.

\section{REFERENCES}

1. Yu CS, Yun HR, Shin EJ, Lee KY, Kim NK, Lim SB, et al. Local excision after neoadjuvant chemoradiation therapy in advanced rectal cancer: a national multicenter analysis. Am J Surg 2013; 206:482-7.

2. Cho YB, Chun HK, Yun HR, Lee WS, Yun SH, Lee WY. Clinical and pathologic evaluation of patients with recurrence of colorectal cancer five or more years after curative resection. Dis Colon Rectum 2007;50:1204-10.

3. Vera R, Aparicio J, Carballo F, Esteva M, Gonzalez-Flores E, Santianes J, et al. Recommendations for follow-up of colorectal cancer survivors. Clin Transl Oncol 2019;21:1302-11.

4. Chakravarti A, Compton CC, Shellito PC, Wood WC, Landry J, Machuta SR, et al. Long-term follow-up of patients with rectal cancer managed by local excision with and without adjuvant irradiation. Ann Surg 1999;230:49-54.

5. Mellgren A, Sirivongs P, Rothenberger DA, Madoff RD, GarciaAguilar J. Is local excision adequate therapy for early rectal cancer? Dis Colon Rectum 2000;43:1064-74.

6. Garcia-Aguilar J, Renfro LA, Chow OS, Shi Q, Carrero XW, Lynn $\mathrm{PB}$, et al. Organ preservation for clinical T2N0 distal rectal cancer using neoadjuvant chemoradiotherapy and local excision (ACOSOG Z6041): results of an open-label, single-arm, multi-institutional, phase 2 trial. Lancet Oncol 2015;16:1537-46.

7. Martens MH, Maas M, Heijnen LA, Lambregts DM, Leijtens JW, Stassen LP, et al. Long-term outcome of an organ preservation program after neoadjuvant treatment for rectal cancer. J Natl Cancer Inst 2016;108:djw171.

8. Cottet V, Bouvier V, Rollot F, Jooste V, Bedenne L, Faivre J, et al. Incidence and patterns of late recurrences in rectal cancer pa- 
tients. Ann Surg Oncol 2015;22:520-7.

9. Merkel S, Meyer T, Gohl J, Hohenberger W. Late locoregional recurrence in rectal carcinoma. Eur J Surg Oncol 2002;28:716-22.

10. Seo SI, Lim SB, Yoon YS, Kim CW, Yu CS, Kim TW, et al. Comparison of recurrence patterns between $\leq 5$ years and $>5$ years after curative operations in colorectal cancer patients. J Surg Oncol 2013;108:9-13.

11. Paty PB, Nash GM, Baron P, Zakowski M, Minsky BD, Blumberg $\mathrm{D}$, et al. Long-term results of local excision for rectal cancer. Ann Surg 2002;236:522-30.

12. Marin G, Suarez J, Vera R, Balen E, Viudez A, Mata E. Local recurrence after five years is associated with preoperative chemoradiotherapy treatment in patients diagnosed with stage II and III rectal cancer. Int J Surg 2017;44:15-20.

13. Sauer R, Liersch T, Merkel S, Fietkau R, Hohenberger W, Hess C, et al. Preoperative versus postoperative chemoradiotherapy for locally advanced rectal cancer: results of the German CAO/ARO/ AIO-94 randomized phase III trial after a median follow-up of 11 years. J Clin Oncol 2012;30:1926-33.

14. Tjandra JJ, Chan MK. Follow-up after curative resection of colorectal cancer: a meta-analysis. Dis Colon Rectum 2007;50: 1783-99.

15. Yang KM, Lim SB, Lee JL, Kim CW, Yoon YS, Park IJ, et al. Local excision for ypT2 rectal cancer following preoperative chemoradiation therapy: it should not be justified. Int J Colorectal Dis 2018;33:487-91. 